\title{
Investigation of catalytic effects of indigenous minerals in the pyrolysis of Aleksinac oil shale organic matter
}

\author{
D. VuČELIĆ, ${ }^{1,2}$ V. MARKović, ${ }^{2}$ V. VuČELIĆ, ${ }^{2}$ D. SPIRIDONOVIĆ, ${ }^{2}$ B. JOVANČIĆEVIIĆ ${ }^{3,4}$ and \\ D. VITOROVIĆ $\dot{C}^{3,4 *}$
}

'Department of Physical Chemistry, University of Belgrade, ${ }^{2}$ Institute of General and Physical Chemistry, Belgrade, ${ }^{3}$ Department of Chemistry, University of Belgrade, P.O. Box 550, 11001 Belgrade and ${ }^{4}$ Institute of Organic Chemistry, Biochemistry and Instrumental Analysis, Belgrade, Yugoslavia

\begin{abstract}
The catalytic effect of indigenous minerals in the pyrolysis of Aleksinac (Yugoslavia) oil shale was studied in this paper. The substrates were prepared by gradual removal of the mineral constituents (carbonates, silicates, pyrite) and the free and bound bitumens. The substrates were analyzed by chemical methods, X-ray diffraction, porosimetry, thermal analysis, ${ }^{13} \mathrm{C}$ NMR, and standard ASTM Micro Activity Test (MAT) designed for the investigation of cracking catalysts. The liquid pyrolysis products were analyzed by organic geochemical techniques as well. Based on the yields of gaseous and liquid products and the coke, conversion degrees, GC analyses (MAT parameters) and weight losses (TG parameter), the catalytic effect of indigenous mineral components in the pyrolysis of Aleksinac oil shale organic matter was found to be very low. The results suggested that principal organic matter changes should be attributed to thermal rather than to catalytic cracking.
\end{abstract}

Key words -oil shale from Aleksinac (Yugoslavia), indigenous minerals, catalytic effects, kerogen, pyrolysis, micro activity test (MAT-ASTM)

\section{INTRODUCTION}

Mineral components are known to have considerable effect on the thermal alteration of sedimentary organic matter (Espitalié et al., 1980; Horsfield and Douglas, 1980; Jeong and Patzer, 1983; Sajgo et al., 1983). Therefore, knowledge of the mineral composition contributes to better understanding of organic matter maturation processes as well as to the interpretation of the various forms of sedimentary organic matter. Also, due to the catalytic effect of some minerals, the yield of gaseous and liquid products in the pyrolysis of oil shales should also be expected to depend on their mineralogical composition. Hence, investigations aimed at identifying the mineral components which interact with sedimentary organic matter and at revealing the mode and intensity of these interactions are of organic geochemical interest.

Studies of interactions between inorganic and organic constituents in sediments have shown that the influence of minerals is caused by adsorption and catalytic effects (e.g., Tannenbaum et al., 1986). It has also been shown that clay minerals, primarily montmorillonite and illite, are most efficient in both adsorption and catalytic effects (Tannenbaum and Kaplan, 1985a,b; Tannenbaum et al., 1986; Huizinga et al., 1987a,b). Thermocatalytic properties of these minerals were demonstrated by the yields and compositions of gaseous and liquid products in pyrolysis experiments with pure kerogen and kerogen to which certain amounts of individual minerals were added.

*To whom all correspondence should be addressed.
The catalytic effect of indigenous minerals in the pyrolysis of Aleksinac (Yugoslavia) oil shale was the subject of the present study. An investigation of the effects of native minerals was chosen rather than added inorganic materials, since the ultimate aim of the study was to influence the pyrolysis by in situ modification (activation or inhibition) of the shale minerals.

The substrates examined were of different mineralogical compositions, i.e. the raw shale and the substrates obtained by gradual removal of the mineral constituents (carbonates, silicates, pyrite) and the free and bound bitumens. It is known that in addition to mineral components, the shale organic matter may also be altered during the demineralization steps. However, since experimental evidence showed that these changes were subordinate, the observed differences in the yields and compositions of gaseous and liquid pyrolysis products were used as a basis for the evaluation of the catalytic effects of indigenous minerals.

\section{MATERIALS AND METHODS}

The oil shale sample, containing $c a 25 \%$ organic matter, originated from the Aleksinac (Yugoslavia) oil shale deposit, a freshwater lake sediment of Upper Oligocene-Lower Miocene. According to atomic $\mathrm{H} / \mathrm{C}-\mathrm{O} / \mathrm{C}$ ratios, the sample contained type I kerogen (C-78.30\%; H-10.23\%; N-2.93\%; H/C-1.57; $\mathrm{O} / \mathrm{C}-0.08)$. A large quantity of the sample $(>50 \mathrm{~kg})$ was powdered in a semi-industrial ball niill $(-80 \mu \mathrm{m})$. 
The substrates were prepared from the raw shale (" $\mathbf{B}_{1}$ ") by gradual removal of the mineral constituents (carbonates, silicates, pyrite) and the free and bound bitumens, according to the scheme shown in Fig. 1.

Samples $\mathbf{B}_{2}, \mathbf{B}_{4}, \mathbf{B}_{6}, \mathbf{B}_{7}$ and $\mathbf{B}_{8}$ were of special interest for the testing of the catalytic activity. $\mathbf{B}_{2}$ represented the bitumen 1 -free raw shale. The sample $B_{4}$ was obtained from $B_{2}$ by treatment with $3 \mathbf{M}$ hydrochloric acid followed by extraction of bitumen 2. Hence, in addition to kerogen (and bitumen 3) sample $B_{4}$ contained silicates and pyrite. The sample $B_{6}$ was obtained from $B_{4}$ by a conc. $\mathrm{HCl}-\mathrm{HF}(1: 1)$ treatment followed by bitumen 3 extraction. The aluminosilicates, for long known as cracking catalysts, were thus removed in this phase of the preparation process. Therefore, sample $\mathbf{B}_{6}$ consisted only of kerogen and pyrite. Two pyrite-free samples were prepared by removal of pyrite with $\mathrm{LiAlH}_{4}$ (Lawlor et al., 1963) from samples $\mathbf{B}_{4}$ and $\mathbf{B}_{6}$.

The substrates were analyzed by chemical analysis, $\mathrm{X}$-ray diffraction, porosimetry, thermal analysis and ${ }^{13} \mathrm{C}$ NMR.

The organic matter content in samples $\mathbf{B}_{\mathbf{4}}-\mathbf{B}_{\mathbf{8}}$ was determined by combustion $\left(850^{\circ} \mathrm{C}\right.$, to constant weight). Analysis of samples containing pyrite included correction for the weight loss involved in the combustion of pyrite.

The amounts of carbonates and silicates in samples $B_{1}$ and $B_{2}$ were estimated on the basis of quantitative data of the samples' preparation procedure (Fig. 1), while the calculation of the amounts of pyrite in all relevant samples $\left(B_{1}, B_{2}, B_{4}\right.$ and $\left.B_{6}\right)$ was based on total sulfur determined by ultimate analysis. The total amount of minerals enabled calculation of organic matter content in samples $B_{1}$ and $B_{2}$. The amount of silicate minerals was determined in samples $\mathbf{B}_{\mathbf{4}}$ and $\mathbf{B}_{6}$ by difference, from the total amount of the sample and the sum of organic matter and pyrite, and in samples $B_{7}$ and $B_{8}$ on the basis of ash obtained by ignition of the samples at $850^{\circ} \mathrm{C}$. Quantitative chemical analysis of iron as well as X-ray diffraction analysis of the substrates confirmed that samples $\mathbf{B}_{7}$ and $\mathrm{B}_{8}$ did not contain pyrite.

Due to limitations of X-ray diffraction analyses (XRD) of the samples such as those examined in this paper, the XRD analyses were used for qualitative assessment of the mineral compositions rather than for quantification of individual phases. They were carried out on a Philips automated powder X-ray diffractometer (APD 1700), and a vertical PW 1820 goniometer. A $\mathrm{CuK} \alpha$ radiation and graphite focusing monochromator on the diffracted beam was employed. Fixed slits were set at: divergence $1^{\circ}$, receiving $0.2 \mathrm{~mm}$ and scatter $1^{\circ}$. Data were collected continuously $\left(2 \theta=5-60^{\circ}\right)$ with sample interval of $0.025^{\circ}$ and speed $0.010^{\circ} / \mathrm{s}$. The oil shale specimens preparation was performed from the $<63 \mu \mathrm{m}$ fractions. Major and minor minerals were identified according to JCPDS (Joint Committee on Powder Diffraction Standards) data base.
The surface area and pore volume were determined from $\mathrm{N}_{2}$ sorption/desorption isotherms (BET method, Quantasorb).

The differential thermal (DTG) and thermogravimetric (TG) analyses aimed mainly at determining optimal temperatures for pyrolytic experiments, were carried out on a Du Pont 951 Thermogravimetric Analyzer as the annexing module of a Du Pont 990 Thermal Analyzer. The samples were heated over a temperature range of $30-900^{\circ} \mathrm{C}$ at $5^{\circ} \mathrm{C} / \mathrm{min}$, in a stream of nitrogen $\left(35 \mathrm{~cm}^{3} / \mathrm{min}\right)$.

A standard ASTM Micro Activity Test (MATASTM D 3907), designed for the investigation of cracking catalysts' activity, was used for the evaluation of the catalytic activity of the native minerals in the pyrolysis of Aleksinac oil shale organic matter. The test consisted of the heating of $\sim 4 \mathrm{~g}$ samples in a nitrogen stream at $580^{\circ} \mathrm{C}$ for $50 \mathrm{~min}$. It involved quantitative and qualitative GC evaluation of gaseous and liquid products. The solid residue was examined for semicoke carbon. In addition the liquid products were analyzed by organic geochemical techniques such as column chromatography and capillary GC. The observed differences between the substrates and their pyrolysis products served as a basis for the estimation of the catalytic effect of individual native minerals.

The analysis of gaseous products was carried out on a Hewlett Packard 5880 A gas chromatograph, with a $10 \mathrm{~m} \times 2 \mathrm{~mm}$ packed column containing $23 \%$ SP-1700 on Chromosorb P-AW, TCD and helium as carrier gas. The temperature of the column, detector and injector was kept at $70^{\circ} \mathrm{C}$. The alkane/alkene ratios $\left(\mathrm{C}_{3}, \mathrm{C}_{4}, \mathrm{C}_{5}\right.$ and $\left.\mathrm{C}_{6}\right)$ were calculated on the basis of gaseous products' chromatograms.

For the sake of the ASTM conversion degree determination, the liquid products were analyzed by gas chromatography (ASTM-D 2887). For that purpose the same Hewlett Packard 5880 A gas chromatograph was used, with a $50 \mathrm{~cm} \times 2 \mathrm{~mm}$ packed column containing $10 \%$ UCW-982 on Chromosorb P-AW, and FID, using hydrogen as carrier gas. The detector and injector temperatures were kept at $350^{\circ} \mathrm{C}$. The column temperature was programmed from 35 to $350^{\circ} \mathrm{C}$ at $10^{\circ} \mathrm{C} / \mathrm{min}$.

The liquid products were also fractionated by column chromatography $\left(\mathrm{Al}_{2} \mathrm{O}_{3} / \mathrm{SiO}_{2}\right)$. The fractions of hydrocarbons, eluted by petroleum ether, were analyzed by GC using a Varian 3300 gas chromatograph, with a $25 \mathrm{~m} \times 0.25 \mathrm{~mm}$ capillary column coated with nonpolar BP-1, FID and hydrogen as carrier gas. The detector and injector temperatures were kept at $300^{\circ} \mathrm{C}$. The column temperature was programmed from 100 to $280^{\circ} \mathrm{C}$, at $6^{\circ} \mathrm{C} / \mathrm{min}$. The alkane/alkene ratios $\left(C_{16}, C_{19}, C_{24}\right.$ and $\left.C_{29}\right)$ were calculated from the gas chromatograms of the hydrocarbon fractions.

The semicoke carbon was determined by combustion at $700^{\circ} \mathrm{C}$. The gaseous products thus obtained were led over $\mathrm{CuO}$ at $400^{\circ} \mathrm{C}$ to oxidize residual 


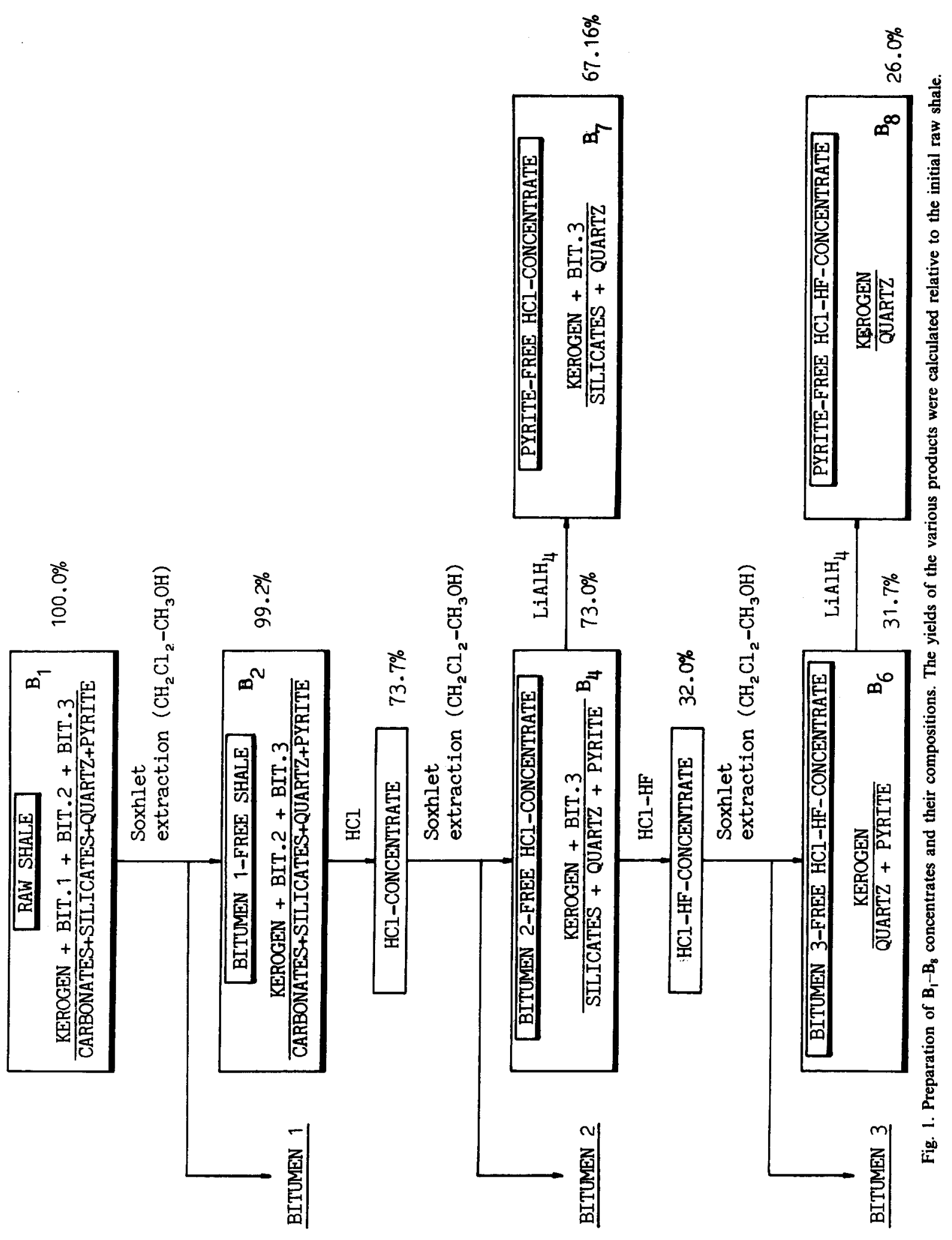



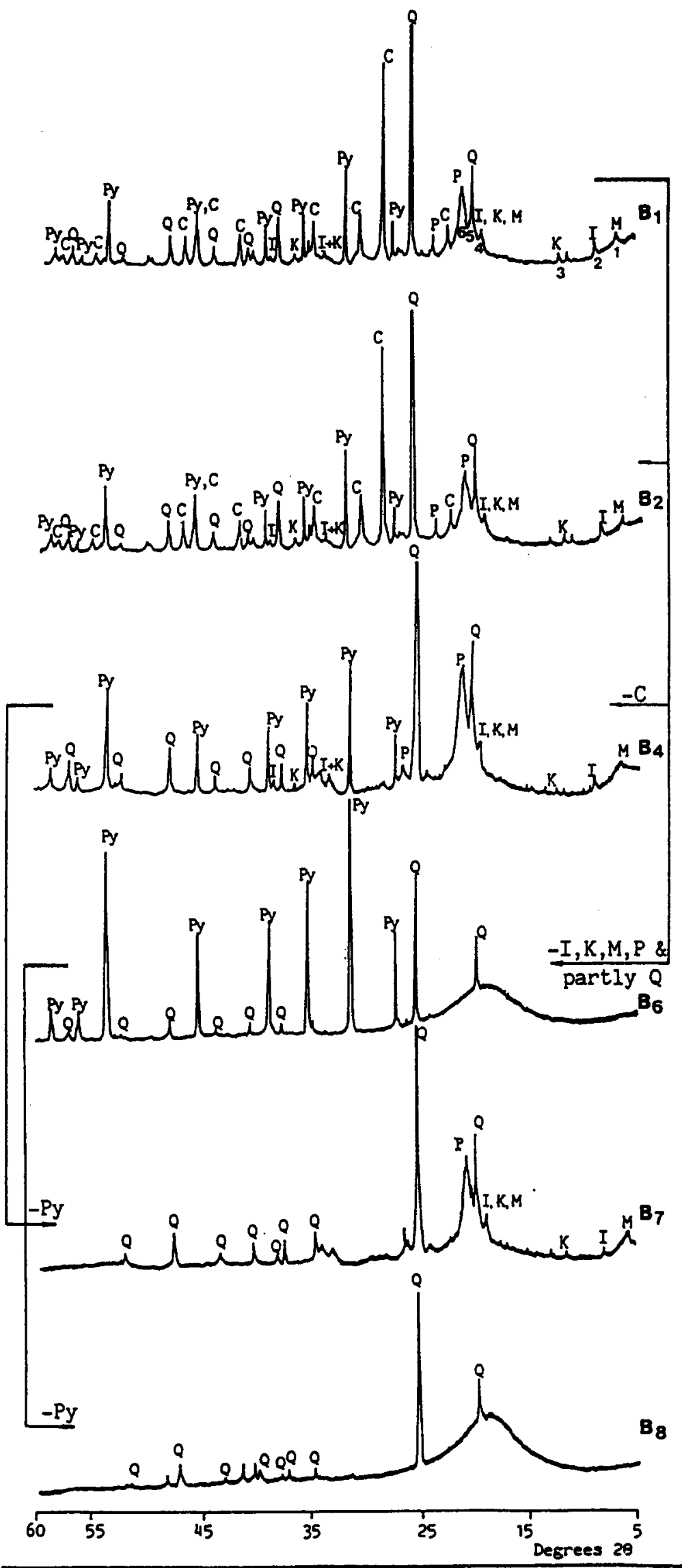

Fig. 2. X-ray diffractograms of the $\mathrm{B}_{1}-\mathrm{B}_{8}$ samples. $\mathrm{C}-$ calcite; $\mathrm{Q}-$ quartz; $\mathrm{P}-$ plagioclase; $\mathrm{I}-$ illite; $\mathrm{K}-$ kaolinite; $\mathrm{M}-$ montmorillonite; Py-pyrite. 
carbon monoxide into dioxide. The carbon dioxide was then absorbed by ascarite.

\section{RESULTS AND DISCUSSION}

\section{Chemical and mineralogical compositions}

The X-ray diffractograms of samples $\mathbf{B}_{1}, \mathbf{B}_{2}, \mathbf{B}_{\mathbf{4}}, \mathbf{B}_{6}$, $B_{7}$ and $B_{8}$, shown in Fig. 2, revealed the differences in the mineral compositions.

$\mathrm{X}$-ray diffraction assignments of several minor mineral phases in sample $B_{1}$ in the range $5-23^{\circ} 2 \theta$ are shown in Table 1.

According to X-ray analyses, the substrates contained calcite $(\mathrm{C})$, quartz $(\mathrm{Q})$, crystobalite $(\mathrm{Cr})$, plagioclase (P), illite (I), kaolinite (K), montmorillonite (M) and pyrite (Py), their proportions changing depending on the degree of demineralization of the raw shale.

The results of quantitative chemical analyses of various substrates are shown in Table 2 .

The contents of organic matter in the substrates reflected the different treatment procedures in the various phases of the substrate preparation (gradual extraction of bitumens and elimination of mineral constituents).

The same applies to the proportions of mineral constituents in diverse substrates.

Samples $\mathbf{B}_{7}$ and $\mathbf{B}_{\mathbf{8}}$ did not contain carbonates nor pyrite. In addition to kerogen the sample $\mathbf{B}_{7}$ contained only aluminosilicates plus quartz (and a small quantity of bitumen 3 ) and the sample $B_{8}$ consisted only of kerogen and residual quartz which was shown to be resistant to the applied acid treatment. Hence, the purest form of kerogen in this study was obtained in sample $\mathbf{B}_{8}$ which contained $86.1 \%$ kerogen and $13.9 \%$ quartz (Table 2).

$\mathrm{CP} / \mathrm{MAS}{ }^{13} \mathrm{C}$ NMR spectra indicated a very high content of aliphatic $(\sim 77 \%)$ and a noticeable content of aromatic and other non-aliphatic carbon $(\sim 23 \%)$ in the Aleksinac shale kerogen (Vučelić et al., 1992).

Surface area and pore volume are important parameters for catalytic activity. The Aleksinac oil shale sample is characterized by a broad pore distribution, but mainly dominated by wide $0.5-10 \mu \mathrm{m}$ pores (determined by mercury porosimetry), with minor amounts of mesopores of 3-10 nm. The corresponding adsorption isotherms (one of them is shown as example in Fig. 3) belongs to a rare group of polymolecular sorption of type III, characterized
Table 1. XRD assignments of several minor mineral phases in sample $B_{1}$ in the range $5-23^{\circ} 2 \theta$

\begin{tabular}{lcl}
\begin{tabular}{l}
$\begin{array}{l}\text { Line number } \\
\text { (cf. Fig. 2) }\end{array}$ \\
\hline 1
\end{tabular} & $\begin{array}{c}d \text { value } \\
(\AA)\end{array}$ & Phases identified \\
\hline 2 & 13.27 & $\mathrm{M}$ \\
3 & 10.10 & $\mathrm{I}$ \\
4 & 7.13 & $\mathrm{~K}$ \\
5 & 4.46 & $\mathrm{M}+\mathrm{I}, \mathrm{K}$ \\
6 & 4.25 & $\mathrm{Q}$ \\
$\mathrm{M}=$ montmorillonite; $\mathrm{I}=$ illite; $\mathrm{K}=$ kaolinite; $\mathrm{Q}=$ quartz; \\
\multicolumn{2}{r}{$\mathrm{Cr}=$ crystobalite; $\mathrm{P}=$ plagioclase. }
\end{tabular}

by weak sorbent/sorbate interaction. Although the isotherm shape did not change from $B_{1}$ to $B_{6}$, the specific surface area $\left(\mathrm{N}_{2}, \mathrm{BET}\right)$ increased from $B_{1}=10$, through $B_{2}=12$, up to $B_{4}=20 \mathrm{~m}^{2} / g$. The significant $\mathbf{B}_{2}-\mathbf{B}_{4}$ increase of the specific surface area indicated that calcite not only did not take part in the sorption but also prevented access to sorption centers. Removal of aluminosilicates caused a drop of the specific surface in $B_{6}$ to only $6 \mathrm{~m}^{2} / \mathrm{g}$, showing that the aluminosilicates were mainly responsible for the sorption. The porosity of $B_{6}$ was relatively uniform $(10-100 \mathrm{~nm})$, representing at the same time the size of aluminosilicate particles in the shale sample.

\section{Catalytic activity}

The evaluation of the catalytic effect of the minerals on pyrolysis of Aleksinac shale organic matter was partly based on thermal analysis (DTG and TG), and primarily on Micro Activity Test (MAT) of the $B_{1}, B_{2}, B_{4}, B_{6}, B_{7}$ and $B_{8}$ samples.

Thermal analysis involved both decompositional effects: pyrolysis and the catalytic cracking. DTG analysis in nitrogen of all six samples is illustrated in Fig. 4.

Stepwise degradation was apparent, including the aliphatic fraction at $310-450^{\circ} \mathrm{C}$ and the rest of functionalized organic matter at $400-500^{\circ} \mathrm{C}$ (Vučelić et al., 1988). The $630-700^{\circ} \mathrm{C}$ peak in thermograms of samples $\mathbf{B}_{1}$ and $\mathbf{B}_{2}$ originated from carbonates, hence it was absent in thermograms of other samples. A pairwise similarity was observed in the thermal degradation profiles of $B_{1}$ and $B_{2}$ vs $B_{4}$ and $B_{6}$ vs $B_{7}$ and $B_{8}$ samples. The $\mathrm{HCl}$-soluble inorganic material in $B_{1}$ and $B_{2}$ as well as pyrite in $B_{4}$ and $B_{6}$ obviously affected, or took part in the thermal decomposition. Surprisingly, no difference was observed between the thermograms of samples $B_{4}$ and $B_{6}$, although $B_{4}$ contained maximum and $B_{6}$ minimum of catalytically

Table 2. Chemical and mineralogical compositions of the examined samples

\begin{tabular}{lcccccc}
\hline Samples & $\mathrm{B}_{1}$ & $\mathrm{~B}_{2}$ & $\mathrm{~B}_{4}$ & $\mathrm{~B}_{6}$ & $\mathrm{~B}_{7}$ & $\mathrm{~B}_{8}$ \\
\hline TOC(\%) & $\mathrm{ND}^{*}$ & $\mathrm{ND}^{*}$ & 29.5 & 57.8 & 29.6 & 66.2 \\
Organic matter (\%) & 24.7 & 23.6 & 36.9 & 73.7 & 40.0 & 86.1 \\
Carbonates (\%) & 25.5 & 25.7 & 0.0 & 0.0 & 0.0 & 0.0 \\
Silicates (\%) & 44.2 & 44.5 & 55.1 & $8.4 \dagger$ & 60.0 & $13.9 \dagger$ \\
$\quad$ Incl. quartz) & & & & & & \\
Pyrite (\%) & 5.6 & 6.2 & 8.0 & 17.9 & 0.0 & 0.0 \\
\hline
\end{tabular}

* Since $B_{1}$ and $B_{2}$ contained carbonates, TOC was not determined in these samples.

+XRD of samples $B_{6}$ and $B_{8}$ indicated that only quartz out of all siliceous minerals remained in these samples. 


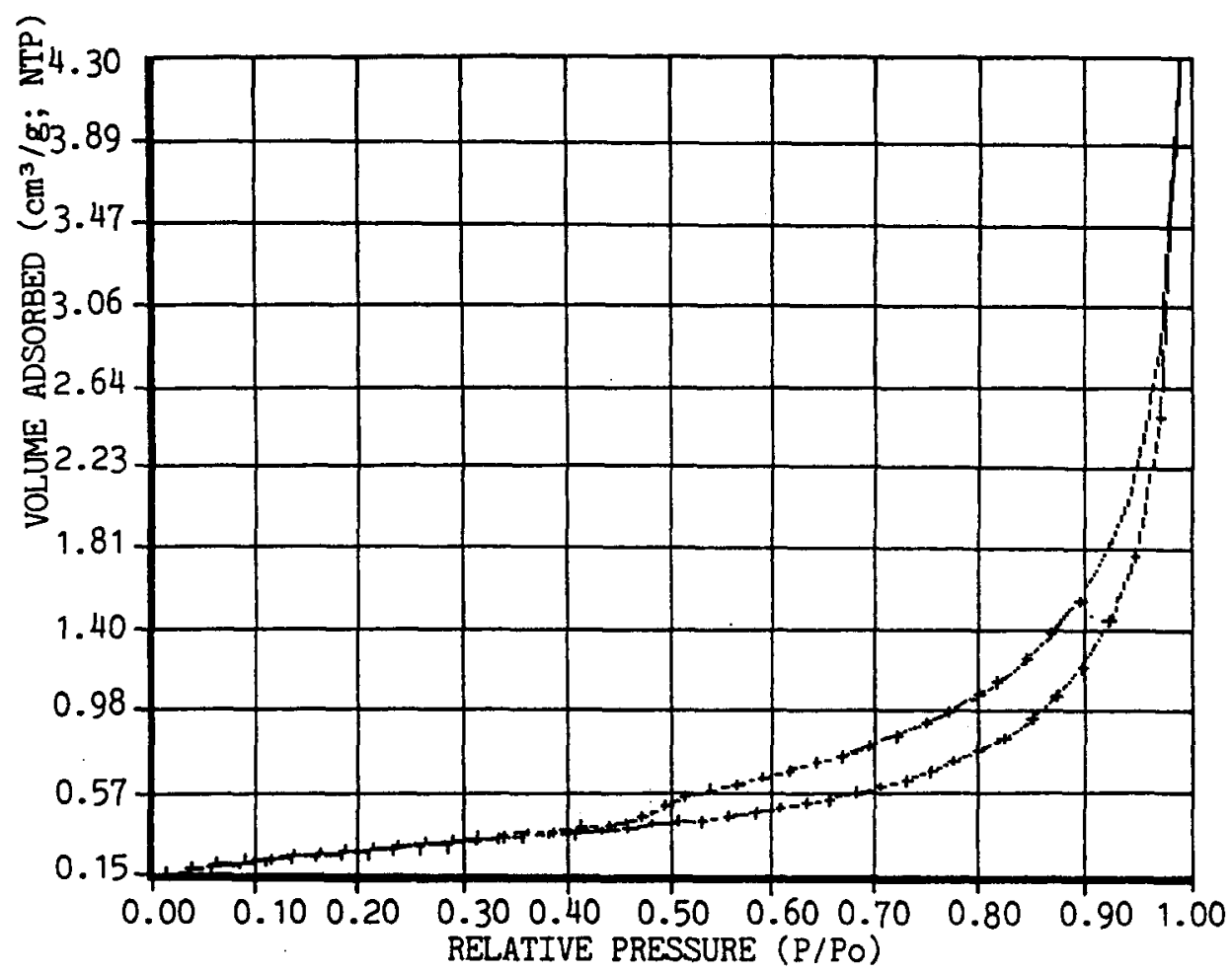

Fig. 3. The adsorption isotherms of nitrogen at $-193^{\circ} \mathrm{C}$ for sample $\mathrm{B}_{4}$. NTP-normal temperature and pressure.

active aluminosilicates. The temperature for MAT $\left(580^{\circ} \mathrm{C}\right)$ was chosen on the basis of DTG analysis of the substrates $B_{1}-B_{6}$.

The total weight losses observed in TG analyses of the tested samples, which might be useful in the evaluation of catalytic activity of the minerals, are given in Table 3.

The weight losses, calculated relative to organic matter, higher than $100 \%$, observed with samples $B_{1}, B_{2}, B_{4}$ and $B_{6}$, are due to decomposition of carbonates and pyrite as well as loss of silicate crystalline water.

The results of one set of MAT are shown as an example in Table 3. The catalytic effect of silicates, pyrite and carbonates on pyrolysis of Aleksinac oil shale organic matter was estimated on the basis of these results. The observed conversion degrees, which usually serve for the evaluation of catalytic activity, were found to be low for all examined substrates $(10.8-19.8 \%)$, i.e. substantially lower than the usual values for aluminosilicates or zeolite catalysts $(50-70 \%)$. This was the case even with the sample $B_{7}$, containing only silicates as mineral components. Consequently, the results suggested that the main organic matter changes should be attributed to thermal rather than to catalytic cracking.

A more detailed specific discussion on the effects of individual Aleksinac oil shale mineral components can be based on pairwise comparative consideration of experimental data (Tables 2 and 3; Figs 1 and 2).
For example, to evaluate the effect of silicates, results obtained for samples $B_{7}$ and $B_{8}$ were compared. Neither of these two samples contained pyrite (which was eliminated by $\mathrm{LiAlH}_{4}$; Fig. 1; Table 2). Sample $\mathrm{B}_{7}$ contained bitumen 3, silicates and quartz, and sample $B_{8}$ was bitumen 3- and silicate-free and contained only some residual quartz (Table 2). Comparison of the corresponding conversion degrees (19.8 and $10.8 \%$, respectively, Table 3 ) suggested a small catalytic effect of indigenous silicates with the sample $\mathbf{B}_{7}$. Thermal cracking as the dominant process in the organic matter change obviously characterized the MAT of the almost ash-free $\mathbf{B}_{8}$ sample. In spite of the low content of catalytically active silicates (e.g., montmorillonite and illite) in the examined oil shale sample (Fig. 2), the small catalytic effect observed with sample $B_{7}$ may be due to the highest relative concentration of the silicates in this sample.

Other MAT observations corroborated the inference on some catalytic effect of indigenous minerals (Table 3). For example, the MAT of the sample $B_{7}$ yielded more liquid and gaseous products than the sample $\mathrm{B}_{8}(57.1$ vs $42.8 \%$ and 3.8 vs $1.6 \%$, respectively, based on initial organic matter). Also, proportionally lower carbon residue (coke) was obtained from $B_{7}$ relative to $\mathbf{B}_{8}(24.7$ vs $29.3 \%$ respectively). Higher coke can be expected from thermal vs catalytic cracking. Another proof of certain catalytic effect of the silicates was obtained by comparing the 


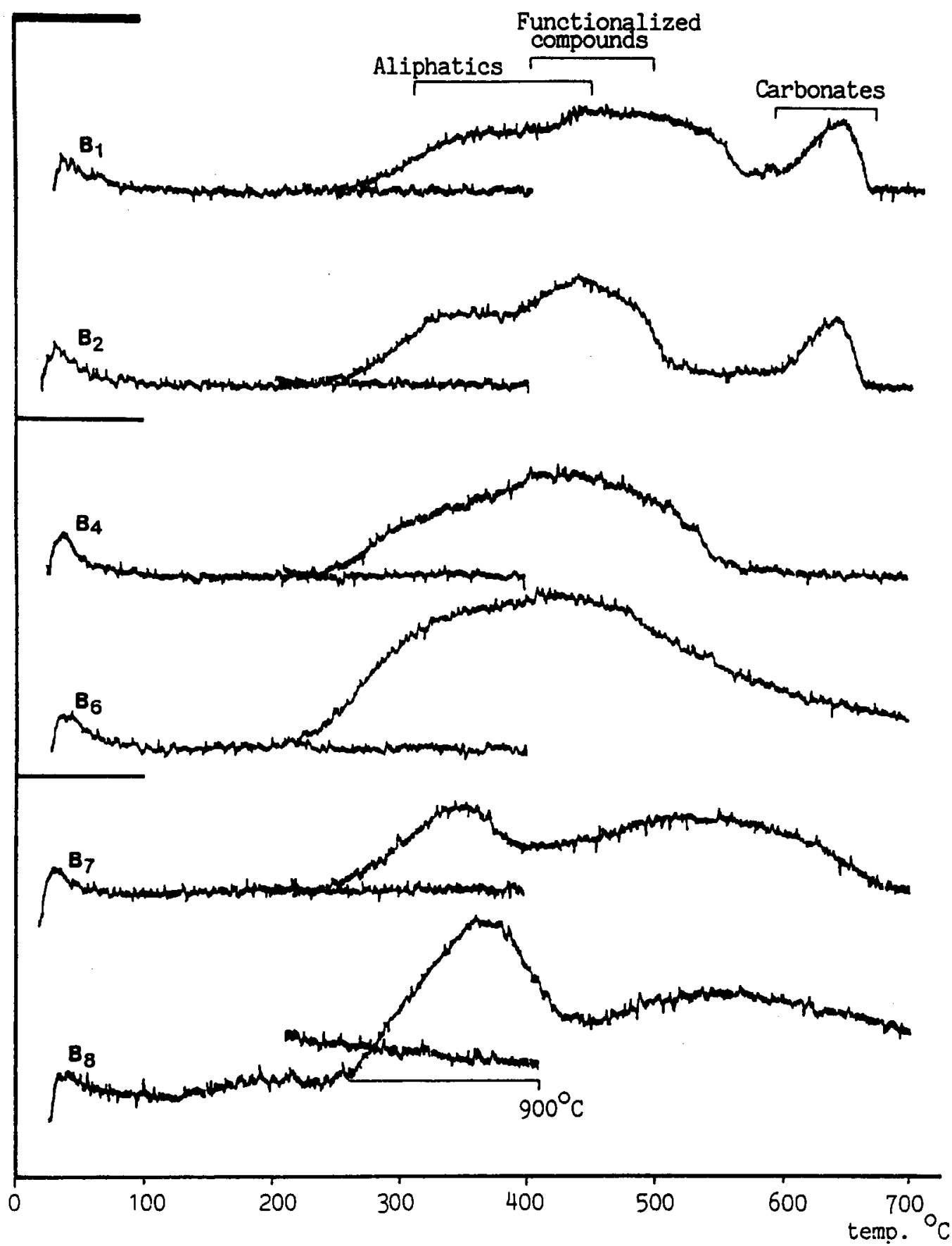

Fig. 4. DTG analyses of $B_{1}-B_{8}$ samples.

TG weight losses for samples $B_{7}$ and $B_{8}(98.8$ vs $96.3 \%$, respectively; Table 3 ).

Furthermore, all the alkane/alkene ratios with both the gaseous and liquid products obtained from samples $B_{7}$ and $B_{8}$ (Table 3) were lower for sample $B_{7}$, indicating at least some catalytic effect of the silicates. Namely, it was shown earlier that by pyrolysis of kerogen in the presence of mineral catalysts (most frequently montmorillonite) the content of aliphatic alkanes in the pyrolysate decreases relative to alkenes
(Tannenbaum and Kaplan, 1985b). Therefore, smaller alkane/alkene ratios with the products of sample $B_{7}$ are most probably due to the catalytic effect of clay minerals, possibly montmorillonite and illite which were found in small proportions in the examined sample of Aleksinac oil shale. It seems justified to presume that all observed differences in MAT and TG behaviour of samples $B_{7}$ and $B_{8}$, although very small, may only be ascribed to the catalytic effect. 
Table 3. Results of MAT and TG analyses used for the estimation of catalytic effects of native minerals on pyrolysis of Aleksinac oil shale organic matter

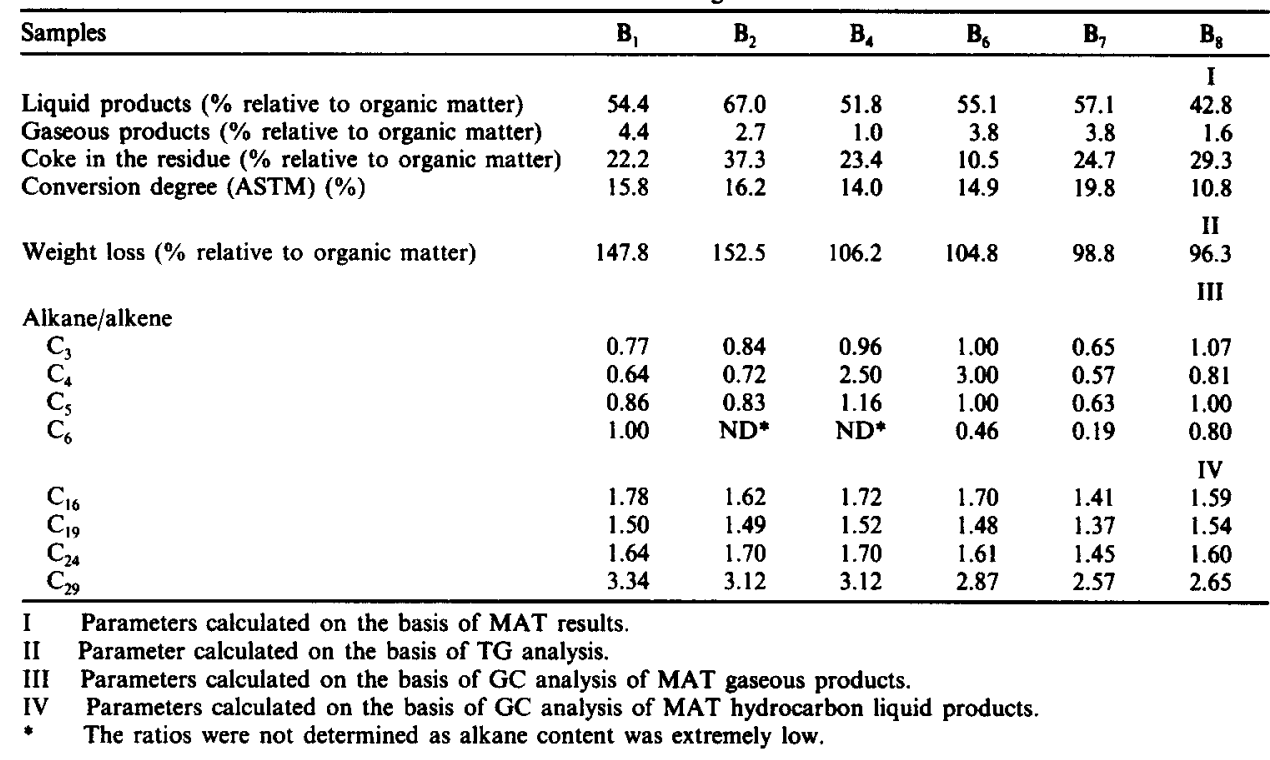

The influence of pyrite on the pyrolysis of Aleksinac shale organic matter is probably complex. The net effect of pyrite should be estimable by direct comparison of the results obtained for samples $B_{6}$ and $B_{8}$. Namely $B_{6}$ consisted of kerogen, quartz and pyrite, and $B_{8}$, being obtained by elimination of pyrite from $\mathbf{B}_{6}$, contained only kerogen and quartz. Comparison of their conversion degrees (14.9 and $10.8 \%$, respectively) suggested a minor catalytic effect of pyrite in spite of the $10 \%$ error of MAT in experiments with oil shales. The yields of liquid and gaseous products and coke as well as TG weight loss (Table 3) corroborate the observed minor catalytic effect of pyrite. The alkane/alkene ratios of gaseous products were also mainly concordant. However, the role of pyrite, otherwise typical catalysts' poison, in the pyrolysis of the shale kerogen, may tentatively be as source of sulfur in the thermal cracking reactions involving formation of organo-sulfur compounds (Jeong and Patzer, 1983). Such presumption may be a further proof of primary role of thermal cracking in the thermal change of the Aleksinac oil shale organic matter.

In the MATs with other samples $\left(\mathbf{B}_{1}, \mathbf{B}_{2}\right.$ and $\left.\mathbf{B}_{4}\right)$ the effect of pyrite cannot be clearly recognized.

Finally, catalytic effect of carbonates was considered by comparing the experimental evidence obtained for samples $B_{2}$ and $B_{4}$ (Tables 2 and 3; Figs 1 and 2). Compared to sample $B_{2}$, sample $B_{4}$ was short of carbonates and bitumen 2. Bearing in mind the possible $10 \%$ experimental error of MAT with these samples, the carbonates do not seem to affect the thermal degradation of Aleksinac oil shale kerogen.

\section{CONCLUSIONS}

The catalytic effect of native minerals in the pyrolysis of Aleksinac oil shale organic matter was esti- mated on the basis of Micro Activity Test-MAT (ASTM D 3907) and thermal analysis (TG and DTG) of a series of samples obtained by gradual removal of mineral components (carbonates, silicates, pyrite) as well as free and bound bitumens (bitumens 1,2 and 3) from the raw shale. The chemical and mineralogical compositions of the various samples were determined by chemical and X-ray diffraction analysis.

On the basis of the yields of gaseous and liquid products and the coke, conversion degrees, GC analyses of gaseous and liquid products (MAT parameters) and weight losses (TG parameter), the following conclusions may be suggested:

(a) Based on low conversion degrees observed with all examined samples (10.8-19.8\%), compared with the $50-70 \%$ conversion degrees with the aluminosilicate or zeolite catalysts, the catalytic effect of indigenous mineral components in the pyrolysis of Aleksinac oil shale organic matter is very low. The results suggested that principal organic matter changes should be attributed to thermal rather than to catalytic cracking.

(b) Some catalytic effect of silicates, probably the clay minerals, was observed in MAT of sample $\mathbf{B}_{7}$. This may be due to the highest relative concentration of the silicates in this sample, compared to other examined samples.

(c) The role of pyrite in the pyrolysis of Aleksinac shale kerogen, observed particularly with the sample $B_{6}$, may be as source of sulfur in the thermal cracking reactions involving formation of organo-sulfur compounds.

(d) The effects of carbonates and quartz were shown to be negligible, particularly bearing in mind the $10 \%$ error of MAT in experiments with oil shale. 
(e) Based on MAT of the almost ash-free $B_{8}$ sample, characterized by pure thermal cracking, the catalytic activities (conversion degrees) with all other samples may be estimated at only 4-8\%.

Acknowledgements - This work was supported in part by the Research Fund of the Republic of Serbia (Yugoslavia).

\section{REFERENCES}

Espitalié J., Madec M. and Tissot B. (1980) Role of mineral matrix in kerogen pyrolysis: influence on petroleum generation and migration. Am. Assoc. Pet. Geol. Bull. 64, $59-66$.

Horsfield B. and Douglas A. G. (1980) The influence of minerals on the pyrolysis of kerogens. Geochim. Cosmochim. Acta 44, 1119-1131.

Huizinga J. B., Tannenbaum E. and Kaplan I. R. (1987a) The role of minerals in the thermal alteration of organic matter-III. Generation of bitumen in laboratory experiments. Org. Geochem. 11, 591-604.

Huizinga J. B., Tannenbaum E. and Kaplan I. R. (1987b) The role of minerals in the thermal alteration of organic matter-IV. Generation of $\boldsymbol{n}$-alkanes, acyclic isoprenoids, and alkanes in laboratory experiments. Geochim. Cosmochim. Acta 51, 1083-1097.
Jeong K. M. and Patzer J. F. (1983) Indigenous mineral matter effects in pyrolysis of Green River oil shale. In Geochemistry and Chemistry of Oil Shales (Edited by Miknis F. P. and McKay J. F.), pp. 529-542. ACS Symposium Series 230, Washington, D.C.

Lawlor D. L., Fester J. I. and Robinson W. E. (1963) Pyrite removal from oil-shale concentrates using lithium aluminum hydride. Fuel 42, 239-244.

Sajgo Cs., Maxwell J. R. and Mackenzie A. S. (1983) Evaluation of fractionation effects during the early stages of primary migration. Org. Geochem. 5, 65-73.

Tannenbaum E. and Kaplan I. R. (1985a) Role of minerals in the thermal alteration of organic matter-I: Generation of gases and condensates under dry condition. Geochim. Cosmochim. Acta 49, 2589-2604.

Tannenbaum E. and Kaplan I. R. (1985b) Low- $M_{\mathrm{r}}$-hydrocarbons generated during hydrous and dry pyrolysis of kerogen. Nature 317, 708-709.

Tannenbaum E., Huizinga J. B. and Kaplan I. R. (1986) Role of minerals in thermal alteration of organic matterII: A material balance. Am. Assoc. Pet. Geol. Bull. 70, 1156-1165.

Vučelić D., Krsmanović V. D., Vučelić V. and Vitorović D. (1988) Partial thermal analysis of kerogen oxidation products. J. Therm. Anal. 34, 1231-1239.

Vučelić M., Vučelić D., Srejić R., Krsmanović V. D. and Vitorovic D. (1992) Characterization of the Aleksinac shale kerogen degradation products by $\mathrm{CP} / \mathrm{MAS}{ }^{{ }^{3} \mathrm{C}}$ NMR. In preparation. 